\title{
Effect of cervical collars on intracranial pressure in patients with head neurotrauma
}

\author{
Luis Rafael Moscote-Salazar ${ }^{1 *}$, Daniel A. Godoy², Amit Agrawal' ${ }^{3}$, Andres M. Rubiano4 \\ 'Neurosurgeon-Critical Care, RED LATINO. Latin American Trauma \& Intensive Neuro-Care Organization, Bogota, Colombia \\ ${ }^{2}$ Unidad de Cuidados Neurointensivos, Sanatorio Pasteur y Unidad de Terapia Intensiva, Hospital San Juan Bautista, Catamarca, \\ Argentina \\ ${ }^{3}$ Department of Neurosurgery, Narayna Medical College Hospital, Chinthareddypalem, Nellore-524003, Andhra Pradesh, India \\ ${ }^{4}$ El Bosque University, RED LATINO. Latin American Trauma \& Intensive Neuro-Care Organization, Bogota, Colombia
}

\section{Dear Editor}

Trauma patients are at high risk of cervical and associated injuries. The standard protocol includes immobilization of the cervical spine in a polytrauma as it will help to prevent spinal injuries in the prehospital settings. Hard cervical collar (or alternatives) is routinely used until the cervical spine clearance is obtained (1-4). In patients with traumatic brain injury avoiding any kind of maneuver may lead to increased intracranial pressure (5). Electronic literature searches were conducted in December 2015 to identify case series (CS) regarding the effect of cervical collars on intracranial pressure in patients with brain trauma injury. The following electronic databases were used: MEDLINE, EMBASE, AMED, CINHAL and Thomson Reuters (formerly ISI). In addition, our own extensive department files were hand-searched for further articles. No restrictions of language or time of publication were imposed. To be included, CS had to pertain to the effect of cervical collars on intracranial pressure in patients with brain trauma injury. Data from spontaneous reporting systems were included. Information from the included CS was extracted according to predefined criteria and assessed by two independent reviewers. Any disagreements were settled through discussion.

Our searches generated 18 articles, of which 14 had to be excluded. Thus, 4 reports met our inclusion criteria (6-9). Our review aimed at summarizing and critically evaluating the available evidence from CS and CR regarding the

\footnotetext{
Received: 25 February 2017; Accepted: 2 May 2017;

Published online: 10 May 2017

*Corresponding author: Dr. Luis Rafael Moscote, Email:

mineurocirujano@aol.com

Competing interests: None.

Funding information: There is none to be declared.

Citation: Moscote-Salazar LR, Godoy DA, Agrawal A, Rubiano AM. Effect of cervical collars on intracranial pressure in patients with head neurotrauma. Journal of Emergency Practice and Trauma 2018; 4(1): 1-2. doi: 10.15171/ jept.2017.03.
}

effect of cervical collar and the intracranial pressure in human patients. According to these reports, the cervical collar has the potential to influence intracranial pressure (possibly a rise in ICP) in patients with traumatic brain injury.

There are several reports in the literature showing that cervical immobilization may alter intracranial pressure and the changes in ICP closely depend on the types of cervical collars used. Placing a cervical collar is a routine procedure and help to reduce the risk of secondary spinal injury, however by altering the ICP it can lead to intracranial injury. It has been shown that patients with severe head injury particularly those who are unstable, unconscious and intubated may have up to $14 \%$ of cervical lesions and up to $7 \%$ of these lesions $(7,9)$. The application of cervical collars has the potential risk to increase intracranial pressure causing obstruction to the venous drainage $(7,9)$. Other adverse effects of cervical immobilization are increased respiratory effort, skin ischemia, pain and discomfort $(10,11)$. There are several limitations to generalize the findings, most of them derived from the design of the included studies. This analysis is directed only to determine the effect of intracranial pressure on cervical collars and it does not pertain to neurological outcome of patients. However, available data for the present analysis are not sufficient to assess this hypothesis. Although this systematic review of case series suggests that an early evaluation of the cervical spine in patients with head trauma is necessary to reduce the impact of prolonged use of cervical collars and their possible influence on intracranial pressure, controlled studies are required to determine the actual effect of immobilization on cervical and intracranial pressure.

Ethical issues

Not applicable.

Authors' contributions

All authors contributed equally to the study. 


\section{References}

1. Dunham CM, Brocker BP, Collier BD, Gemmel DJ. Risks associated with magnetic resonance imaging and cervical collar in comatose, blunt trauma patients with negative comprehensive cervical spine computed tomography and no apparent spinal deficit. Crit Care 2008; 12(4): R89. doi: 10.1186/cc6957.

2. Ho AMH, Fung KY, Joynt GM, Karmakar MK, Peng Z. Rigid cervical collar and intracranial pressure of patients with severe head injury. J Trauma 2002; 53(6): 1185-8.

3. Lemyze M, Palud A, Favory R, Mathieu D. Unintentional strangulation by a cervical collar after attempted suicide by hanging. Emerg Med J 2011; 28(6): 532. doi: 10.1136/ emj.2010.106625.

4. Stone MB, Tubridy CM, Curran R. The effect of rigid cervical collars on internal jugular vein dimensions. Acad Emerg Med 2010; 17(1): 100-2. doi: 10.1111/j.15532712.2009.00624.x.

5. Carter KJ, Dunham CM, Castro F, Erickson B. Comparative analysis of cervical spine management in a subset of severe traumatic brain injury cases using computer simulation.
PloS One 2011; 6(4): e19177. doi: 10.1371/journal. pone.0019177.

6. Craig GR, Nielsen MS. Rigid cervical collars and intracranial pressure. Intensive Care Med 1991; 17(8): 504-5.

7. Davies G, Deakin C, Wilson A. The effect of a rigid collar on intracranial pressure. Injury 1996; 27(9): 647-9.

8. Kuhnigk H, Bomke S, Sefrin P. Effect of external cervical spine immobilization on intracranial pressure. Aktuelle Traumatol 1993; 23(8): 350-3. [In German].

9. Mobbs RJ, Stoodley MA, Fuller J. Effect of cervical hard collar on intracranial pressure after head injury. ANZ J Surg 2002; 72(6): 389-91.

10. Como JJ, Thompson MA, Anderson JS, Shah RR, Claridge JA, Yowler CJ, et al. Is magnetic resonance imaging essential in clearing the cervical spine in obtunded patients with blunt trauma? J Trauma 2007; 63(3): 544-9. doi: 10.1097/ TA.0b013e31812e51ae.

11. Ham W, Schoonhoven L, Schuurmans MJ, Leenen LPH. Pressure ulcers from spinal immobilization in trauma patients: a systematic review. J Trauma Acute Care Surg 2014; 76(4): 1131-41. doi: 10.1097/TA.0000000000000153. 